\title{
ROMANO, Tiago'.
}

SILVA, Fernando Henrique Rugno da ${ }^{1}$.

Resumo: É inconcebível garantir um estado democrático de direito e uma sociedade civil justa e fraterna sem órgãos que defendam as leis e normas vigentes. A Ordem dos Advogados do Brasil, sendo um ente federal contribui para o pleno exercício da cidadania e democracia no Brasil, compreendendo os Estados, Distrito Federal e Municípios. A $5^{\text {a }}$ Subseção nesse ano completa 85 anos de fundação e contribui para o crescimento e desenvolvimento da cidade de Araraquara que nesse mesmo ano completa 200 anos de fundação, exercendo sua função social na sociedade araraquarense. A OAB não é apenas uma instituição de classe e sim uma instituição que tem uma responsabilidade social muito grande, prevista pela própria Constituição Federal. A 5 a Subseção da Ordem dos Advogados do Brasil sediada em Araraquara conta com uma estrutura completa que visa atender aos advogados, advogadas, estagiários e estagiárias, bem como a população, os órgãos públicos, entidades etc.

Palavras-chave: Araraquara; cidadania; Ordem; Advogado; Democracia.

THE 5TH SUBSECTION OF THE ADVOCATE OF BRAZIL AND THE GUARANTEE OF CITIZENSHIP AND DEMOCRACY IN THE 200 YEARS OF THE ARARaQUARa FOUNDATION

Abstract: It is inconceivable to guarantee a democratic state of law and a just and fraternal civil society without bodies that defend the laws and regulations in force. The Brazilian Bar Association, being a federal body, contributes to the full exercise of citizenship and democracy in Brazil, including the States, Federal District and Municipalities. The 5th Subsection this year completes 85 years of foundation and contributes to the growth and development of the city of Araraquara, which in that same year completes 200 years of foundation, exercising its social function in the Araraquara society. The OAB is not only a class institution but an institution that has a very large social responsibility, provided by the Federal Constitution itself. The 5th Subsection of the Brazilian Bar Association based in Araraquara has a complete structure to assist lawyers, lawyers, trainees and trainees, as well as the population, public agencies, entities, etc.

Keywords: Araraquara; Citizenship; Order; Lawyer; Democracy. 


\section{INTRODUÇão}

É preciso, em primeiro lugar entender o significado do vocábulo "ordem”, que nos faz evocar as clássicas agremiações: associações de classe que sempre existiram, desde as sociedades secretas ligadas a alguma religião, como os magos orientais ou órficos gregos, organizados em colégios mais ou menos fechados, mais ou menos exotéricos, até as sociedades profissionais modernas, passando pelo fenômeno especial da maçonaria e conotando a mobilidade social dos séculos mais recentes. Ordens houve na Idade Média no sentido religioso, reunindo agregações oficializadas ou não pela chancela da Igreja Romana. Tanto a Ordem dos Templários como a dos Beneditinos, tanto a de São Francisco, baseada num fascínio pessoal, como posteriormente, já na Idade Moderna a Companhia de Jesus, fundada por um miliciano (ROLLO, et al., 2000).

Em certos momentos da História Contemporânea, como durante o fascismo italiano ou outros, o perfil corporativo das associações profissionais foi absorvido pelo Estado Totalitário, que lhes deu cunho oficial e os pôs em dependência política em face das decisões governamentais e da orientação partidário-ideológica dominante. Falava-se inclusive de representação corporativa: ideia em si não deixava de ter alguns lados positivos, mas no contexto a "representação" se tornava artificial. Com a volta da democracia à maior parte dos países ocidentais, o espirito das agremiações de classe retomou sua conotação essencialmente liberal, o que, no caso das organizações de Advogados e Advogadas, se evidenciava com a retomada de uma vocação retórica e ao mesmo tempo crítica, ao mesmo tempo formalística e referida a valores, ligada ao individualismo e, entretanto com dimensão social (SALDANHA, et al.,1982).

\section{A Constituinte de 1.823 e os cursos jurídicos}

A difusão da formação de uma cultura jurídica no Brasil Independente, proporcionando o incremento do sistema jurídico inaugurado com a primeira Carta Magna brasileira, outorgada em 1.824, remete a dois fatore principais: a criação dos primeiros cursos jurídicos em 1.827, de importância crucial para a consolidação da vida política e intelectual da nação soberana e a fundação, em 1.843, do Instituto dos Advogados Brasileiros(ORDEM DOS ADVOGADOS DO BRASIL, 2017).

Foi nos debates da Assembleia Constituinte de 1.823, logo após a Proclamação da Independência e num momento de definição do Estado Nacional, que se iniciaram as discussões sobre a instalação de cursos jurídicos no Brasil. José Feliciano Fernandes Pinheiro, futuro Visconde de São Leopoldo apresentou, em sessão de 14 de junho de 1.823, indicação pioneira de instalação de uma universidade no Império do Brasil. Tratava-se do lançamento das bases da instrução nacional no "código sagrado" e "de uma maneira digna das luzes do tempo e da sabedoria dos seus colaboradores". Na sessão de 19 de agosto de 1.823 , a indicação se transformava no primeiro projeto de lei que fundava e organizava uma universidade no Brasil(ORDEM DOS ADVOGADOS DO BRASIL, 2017).

A indicação do futuro Visconde de São Leopoldo e oprojeto de lei colocado à apreciação apresentaram, desde o primeiro momento, problemas que seriam a tônica das discussões que agitariam a Assembleia nos meses seguintes: a localização das universidades e a seleção das cadeiras. O debate em torno da localização processou-se de forma apaixonada. Advogando mais em favor das províncias de origem, os parlamentares exaltavam as qualidades de suas terras natais. Montezuma saiu em defesa da Bahia. Muniz Tavares preferia Pernambuco. Silva Lisboa (Visconde de Cairu) formalizou um projeto de universidade na Corte. Outros a queriam na Paraíba e houve proposições também para Minas Gerais.Em 04 de novembro o projeto foi aprovado com emendas, permanecendo, entretanto, a localização original das universidades: São Paulo e Olinda.A eloquência parlamentar em prol do aprimoramento intelectual, que daria ao Brasil soberano sua maioridade cultural, foi frustrada com a dissolução da Constituinte, em 12 de novembro de 1.823. Não era ainda o momento da criação dos cursos jurídicos no Brasil. O Conselho de Estado, que foi instituído logo após o fechamento da Assembleia, para secundar o Imperador, ficou encarregado de elaborar a Constituição, afinal outorgada em 1.824 e não estudaria a instalação de universidades no País(ORDEM DOS ADVOGADOS DO BRASIL, 2017).

\section{A criação dos cursos jurídicos em 1827}

A criação dos cursos jurídicos, uma exigência da cultura brasileira em face da Independência Nacional, era uma decorrência inevitável da militância liberal. Em 1.825, o Imperador instituiria, por decreto de 09 de janeiro, um curso jurídico na cidade do Rio de Janeiro, regido pelos estatutos elaborados por Luís José de Carvalho e Melo e Visconde da Cachoeira. Este curso, entretanto, não chegou a ser inaugurado (ORDEM DOS
ADVOGADOS DO BRASIL, 2017).

A questão foi retomada pelo Parlamento em 1.826. Um projeto de nove artigos, assinado por José Cardoso Pereira de Melo, Januário da Cunha Barbosa e Antônio Ferreira França, que receberia várias emendas, transformou-se na Lei de 11 de agosto de 1.827. Era o encerramento de uma ingente luta em favor da ideia semeada pelo Visconde de São Leopoldo, sob a forma de universidade, na Constituinte de 1.823. Mais tarde o visconde, que teve seu nome definitivamente ligado à lei que iniciava uma fase nova na cultura nacional, faria questão de dizer que esse foi um dos momentos mais gratos de sua vida de homem público (ORDEM DOS ADVOGADOS DO BRASIL, 2017).

Os mesmos estatutos elaborados pelo Visconde da Cachoeira, por ocasião do decreto que tencionara criar o curso jurídico do Rio de Janeiro, regulariam os cursos de Olinda e São Paulo. O Curso de Ciências Jurídicas e Sociais da Academia de São Paulo, que começou a funcionar em $1^{\circ}$ de março de 1.828 e o Curso de Ciências Jurídicas e Sociais de Olinda, inaugurado em 15 de maio de 1.828, representaram marcos referenciais da nossa história, cujo propósito era a formação da elite administrativa brasileira (ORDEM DOS ADVOGADOS DO BRASIL, 2017).

A fundação, em 1.843, do Instituto dos Advogados - que, ao lado do Instituto Histórico e Geográfico Brasileiro, fundado em 1.838, participou de forma incisiva na construção da identidade nacional -, assentaria em bases mais sólidas a atuação desses bacharéis (ORDEM DOS ADVOGADOS DO BRASIL, 2017).

A iniciativa da fundação do Instituto dos Advogados foi inspirada pelas entidades congêneres existentes na França e em Portugal e tinha por finalidade reunir os "cultores" e "agitadores" do Direito, que viriam constituir a Ordem dos Advogados, regularizar o serviço de administração da justiça e completar a organização do Poder Judiciário. A maioria de seus fundadores era composta de graduados das primeiras turmas dos cursos de Olinda e São Paulo, e além da Advocacia, alguns serviam à magistratura, atuavam no Legislativo, no Executivo em Ministérios, ou no Conselho de Estado. Quase todos os integrantes eram membros do Instituto Histórico e Geográfico Brasileiro (ORDEM DOS ADVOGADOS DO BRASIL, 2017).

\section{A fundação do Instituto dos Advogados Brasileiros}

O ministro do Supremo Tribunal de Justiça, Conselheiro Francisco Alberto Teixeira de Aragão, que havia proposto a fundação de uma entidade brasileira nos mesmos moldes da portuguesa, criada em 1.838, sugeriu a criação de uma entidade que facilitasse, quando fosse oportuno, o advento da Ordem dos Advogados. Ele próprio articularia esse empreendimento, fundando na Corte, em janeiro de 1.843, a Gazeta dos Tribunais, um periódico preocupado com a transparência dos atos da justiça e com questões importantes do Direito. Já no primeiro número, a Gazeta publicou um artigo intitulado "A Necessidade de uma Associação de Advogados" e, em 16 de maio de 1.843, divulgou os estatutos da Associação dos Advogados de Lisboa, aprovados por portaria de 23 de março de 1.838. Após um mês, aproximadamente, teve início a discussão em torno da criação de uma corporação que reunisse e disciplinasse a classe de advogados (ORDEM DOS ADVOGADOS DO BRASIL, 2017).

Profundamente influenciados pelos estatutos da associação portuguesa, "inclusive no que dizia respeito à finalidade primordial da instituição: a constituição da Ordem dos Advogados", um grupo de advogados, reunidos na casa do Conselheiro Teixeira de Aragão, organizou os estatutos do Instituto dos Advogados Brasileiros. Submetido à apreciação do Governo Imperial, recebeu aprovação pelo Aviso de 07 de agosto de 1.843. O artigo $2^{\circ}$ dos estatutos da nova instituição dispunha "o fim do Instituto é organizar a Ordem dos Advogados, em proveito geral da ciência da jurisprudência"(ORDEM DOS ADVOGADOS DO BRASIL, 2017).

Em 21 de agosto de 1.843, foi eleita a primeira diretoria do Instituto dos Advogados Brasileiros,composta por Francisco Gê Acaiaba de Montezuma, presidente; Josino Nascimento Silva, secretário da assembleia; Nicolau Rodrigues dos Santos França, tesoureiro e mais 10 nomes que formaram o Conselho Diretor. O Conselheiro Teixeira de Aragão foi agraciado com o título de presidente honorário. A instalação solene ocorreu em 07 de setembro de 1.843, no salão nobre do Externato do Colégio Pedro II, no Rio de Janeiro. O presidente Montezuma proferiu, na ocasião, discurso no qual justificou a criação do Instituto e a sua participação para a criação futura da Ordem dos Advogados. "Ela, Senhores", afirmou referindo-se à Ordem, "não só saberá zelar o subido valor que acaba de receber do Imperante, mas desvelar-se-á por tornar-se digna, em todas as épocas de suas existências, da mais plena e imperial confiança"(ORDEM DOS ADVOGADOS DO BRASIL, 2017).

E o IAB, de certa forma, conseguiu atingir o objetivo de auxiliar o governo na organização legislativa e Revista Brasileira Multidisciplinar - ReBraM vol 20, (supl.) n.1 - Araraquara 200 anos 
judiciária do País, colocando-se como órgão de estudos e debates de questões legislativas e de jurisprudência. Sua atuação na vida nacional caminhou em estreita convergência com o processo de construção do Estado brasileiro. Tanto que a própria Constituição de 1.891, o alicerce da $1^{a}$ República, fora amparada pelos estudos oferecidos pelo IAB, que, revisados por Rui Barbosa, transformaram-se no anteprojeto submetido e aprovado pela Assembleia Constituinte (ORDEM DOS ADVOGADOS DO BRASIL, 2017).

Quanto à criação da Ordem dos Advogados, foram muitas as iniciativas para cumprir o que estabelecia o artigo $2^{\circ}$ dos Estatutos do Instituto dos Advogados Brasileiros. Uma dezena de estudos e projetos elaborados pelo Instituto foi apresentada à apreciação do Poder Legislativo, do Ministério da Justiça e do Governo Imperial, mas todos foram detidos em sua marcha (ORDEM DOS ADVOGADOS DO BRASIL, 2017).

\section{A Revolução de 1.93}

A Primeira República (1.889-1.930), não promoveu um aumento da participação popular no âmbito do sistema político. A presença das camadas médias na cena política só começou a ganhar alguma visibilidade no Brasil após a Primeira Guerra Mundial. Foi quando fatores como as mudanças na estrutura socioeconômica, promovidas principalmente pela desvalorização do café e pelo crescimento industrial, e os desgastes provocados pelas disputas oligárquicas nas sucessões presidenciais ensejaram movimentos que defendiam a ascensão de uma república verdadeiramente liberal. Em contraposição à chamada política do café-com-leite, reivindicavam-se eleições livres, governo constitucional e plenas liberdades civis. Um indício dessa maior participação política foi a eleição de 1.919. Na ocasião, Rui Barbosa, que já havia sido derrotado nas eleições de 1.910 e 1.914, decidiu realizar um protesto, apresentando-se como candidato. Obteve, sem qualquer apoio da máquina eleitoral, cerca de um terço dos votos, além de conseguir a vitória no Distrito Federal (ORDEM DOS ADVOGADOS DO BRASIL, 2017).

A Revolução de 1.930 fez nascer um novo Estado, que se distanciou do modelo oligárquico pelo caráter centralizador e pela maior autonomia. E, ainda que fosse caracterizada pela heterogeneidade dos grupos comprometidos - que conseguiu aliar uma parcela das oligarquias regionais a um grupo de oficiais descontentes egressos do movimento tenentista e intelectuais liberais -, e por uma troca da elite processada sem grandes rupturas, a revolução fez emergir novas forças no cenário político. Foi o caso dos profissionais liberais e dos jovens políticos que, antes de 1.930, formaram a Aliança Liberal e articularam o golpe de estado, como Getúlio Vargas, Osvaldo Aranha, Flores da Cunha, Lindolfo Collor e Francisco Campos, entre outros (ORDEM DOS ADVOGADOS DO BRASIL, 2017).

\section{A criação da Ordem dos Advogados do Brasi}

Foi nesse contexto, e em sintonia com as aspirações de renovação e modernização do País, que se deu a criação da Ordem dos Advogados do Brasil, tendo como personagem central a figura do então Procurador-Geral do Distrito Federal, André de Faria Pereira (ORDEM DOS ADVOGADOS DO BRASIL, 2017).

Logo depois de instalado o Governo Provisório, André de Faria Pereira expôs a Osvaldo Aranha, então ministro da Justiça, a necessidade de modificar a organização da Corte de Apelação, visando à normalização dos seus serviços e ao aumento da produtividade de seus julgamentos. Incumbido pelo ministro de organiza um projeto de decreto, o procurador-geral, há muito sócio do Instituto dos Advogados, incluiu o dispositivo do artigo 17, criando a Ordem dos Advogados. O êxito da iniciativa foi, segundo ele, um milagre(ORDEM DOS ADVOGADOS DO BRASIL, 2017).

A instituição da Ordem dos Advogados do Brasil ocorreu, então, quase um século após a fundação do Instituto dos Advogados, por força do artigo 17 do Decreto $\mathrm{n}^{\circ} 19.408$, de 18 de novembro de 1.930, assinado por Getúlio Vargas, chefe do Governo Provisório, e referendado pelo ministro da Justiça Osvaldo Aranh (ORDEM DOS ADVOGADOS DO BRASIL, 2017).

\section{O início do funcionament}

Como determinava o Decreto $\mathrm{n}^{\circ} 19.408$, a Ordem seria regida pelos estatutos votados pelo Instituto dos Advogados Brasileiros e aprovados pelo governo. O presidente do Instituto, Levi Carneiro nomeou então uma comissão para a elaboração de anteprojeto, formada por A. Moitinho Dória, presidente; Armando Vidal, relator; Edmundo de Miranda Jordão, Antônio Pereira Braga, Edgard Ribas Carneiro, Gabriel Bernardes e Gualter Ferreira. Coube ao próprio Levi Carneiro, desta vez como consultor-geral da República, emitir, em 15 de novembro de 1.931, parecer sobre o projeto do primeiro Regulamento da Ordem dos Advogados, que foi aprovado pelo Decreto $\mathrm{n}^{\circ} 20.784$, de 14 de dezembro de 1.931. O artigo $4^{\circ}$ do Regulamento previa a criação do Conselho Federal para o exercício das atribuições da Ordem em todo o território nacional (ORDEM DOS do Conselho Federal para o exercício

Para Levi Carneiro, a Revolução de 1.930 tinha dado à Ordem dos Advogados do Brasil um alto significado.Em virtude das dificuldades encontradas para implantar a Ordem em todo o território nacional, o Decreto $\mathrm{n}^{\mathrm{o}} 22.266$, de 28 de dezembro de 1.932, adiou para 31 de março de 1.933 a execução do Regulamento, inicialmente prevista para $1^{\circ}$ de maio de 1.932 . E o Decreto $\mathrm{n}^{\circ} 22.478$, de 20 de fevereiro de 1.933 , aprovou e mandou consolidar, com as modificações posteriores introduzidas pelos Decretos $\mathrm{n}^{\circ} 21.592$, de $1^{\circ}$ de julho de $1932 \mathrm{e} \mathrm{n}^{\mathrm{o}} 22.039$, de $1^{\circ}$ de novembro de 1.932, os dispositivos regulamentares da Ordem dos Advogados do Brasil(ORDEM DOS ADVOGADOS DO BRASIL, 2017)

\section{Instalação do Conselho Federal}

O Conselho Federal da OAB funcionou primeiramente no prédio do Instituto dos Advogados brasileiros. A primeira sessão preparatória foi realizada em 06 de março de 1.933 e, em 09 de março, na segunda sessão preparatória, foi realizada a eleição da diretoria, sendo aclamados Levi Carneiro para a presidência e AttílioVivácqua para a secretaria geral. Em sessão especial, nesse mesmo dia, houve a instalação solene do Conselho Federal, completando a aparelhagem da Ordem dos Advogados do Brasil. O Regimento Interno do Conselho, fixando sua organização administrativa, foi aprovado em 13 de março de 1.933 (ORDEM DOS ADVOGADOS DO BRASIL, 2017)

Na solenidade de instalação da primeira sessão ordinária do Conselho Federal, ocorrida em 11 de agosto de 1.933, Levi Carneiro referiu-se à etapa vencida pela instituição em brilhante discurso.E sob a condução de Levi Carneiro e AttílioVivácqua - que foram sucessivamente reeleitos e permaneceram à frente do Conselho Federal por três mandatos consecutivos -, a Ordem dos Advogados foi consolidada. Suas ações concentraramse, principalmente, nas tarefas de organização da instituição, como solução de problemas de interpretação do Estatuto, ordenamento das seções estaduais e elaboração do Código de Ética.O primeiro Código de Ética Profissional para os advogados, aspiração já antiga da classe, foi aprovado na sessão do Conselho Federal de 25 de julho de 1.934, dando cumprimento ao preceituado no artigo 84, inciso III, do Regulamento da OAB,encerrando a discussão iniciada em 30 de maio de 1.933(ORDEM DOS ADVOGADOS DO BRASIL, 2017).

\section{A constituição da secional paulista}

Em 22 de janeiro de 1.932 a secional paulista da Ordem dos Advogados do Brasil ganhou corpo. Na sede do Instituto da Ordem dos Advogados do Brasil foi realizada a primeira reunião, ocasião em que foi indicado como presidente provisório Plínio Barreto e os diretores: Francisco Morato,VicenteRáo, José Joaquim Cardoso de Mello Neto, Ernesto Leme, José Bennaton Prado, Christóvam Prates da Fonseca e Henrique Bayma(ORDEM DOS ADVOGADOS DO BRASIL, 2017)

A previsão legal da existência da ordem dos advogados do brasil, suas secionais estaduais e do distrito federal e suas subseç̃̃es

A Constituição Federal, promulgada em 05 de outubro de 1.988 guindou a Advocacia no seu artigo 133 a "função essencial à administração da justiça"e é a única profissão no Brasil a qual a Carta Federativa estabelece que é essencial a democracia e a cidadania.

Pois bem, para atender a essa disposição constitucional a Lei Federal ${ }^{\circ}$ 8.906, de 04 de julho de 1.994 dispõe sobre o Estatuto da Advocacia e a Ordem dos Advogados do Brasil, estabelecendo que não há hierarquia nem subordinação entre advogados, magistrados e membros do Ministério Público, devendo todos tratar-se com consideração e respeito recíprocos.

A Ordem dos Advogados do Brasil é considerada entidade de caráter público, dotada de personalidade jurídica e forma federativa e tem por finalidade: defender a Constituição, a ordem jurídica do Estado democrático de direito, os direitos humanos, a justiça social, e pugnar pela boa aplicação das leis, pela rápida administração da justiça e pelo aperfeiçoamento da cultura e das instituições jurídicas e promover, com exclusividade, representação, a defesa, a seleção e a disciplina dos advogados em toda a República Federativa do Brasil.

A OAB não mantém com órgãos da Administração Pública qualquer vínculo funcional ou hierárquico, Revista Brasileira Multidisciplinar - ReBraM vol 20, (supl.) n.1 - Araraquara 200 anos 
sendo seus órgãos: o Conselho Federal, os Conselhos Secionais, as Subseções e as Caixas de Assistência dos Advogados.

\section{O conselho federal}

Órgão dotado de personalidade jurídica própria, com sede na capital da República, é o órgão supremo da OAB. Compete ao mesmo: dar cumprimento efetivo às finalidades da $\mathrm{OAB}$; representar, em juízo ou for dele, os interesses coletivos ou individuais dos advogados; velar pela dignidade, independência, prerrogativas e valorização da advocacia;representar, com exclusividade, os advogados brasileiros nos órgãos e eventos internacionais da advocacia;editar e alterar o Regulamento Geral, o Código de Ética e Disciplina, e os Provimentos que julgar necessários; adotar medidas para assegurar o regular funcionamento dos Conselhos Secionais; intervir nos Conselhos Secionais, onde e quando constatar grave violação dos regimentos da $\mathrm{OAB}$ cassar ou modificar, de ofício ou mediante representação, qualquer ato, de órgão ou autoridade da OAB, contrário a esta lei, ao regulamento geral, ao Código de Ética e Disciplina, e aos Provimentos, ouvida a autoridade ou o órgão em causa; julgar, em grau de recurso, as questões decididas pelos Conselhos Secionais, nos casos previstos neste estatuto e no regulamento geral;dispor sobre a identificação dos inscritos na OAB e sobre os respectivos símbolos privativos; apreciar o relatório anual e deliberar sobre o balanço e as contas de sua diretoria; homologar ou mandar suprir relatório anual, o balanço e as contas dos Conselhos Secionais; elabora as listas constitucionalmente previstas, para o preenchimento dos cargos nos tribunais judiciários de âmbito nacional ou interestadual, com advogados que estejam em pleno exercício da profissão, vedada a inclusão de nome de membro do próprio Conselho ou de outro órgão da OAB; ajuizar ação direta de inconstitucionalidade de normas legais e atos normativos, ação civil pública, mandado de segurança coletivo, mandado de injunção e demais ações cuja legitimação lhe seja outorgada por lei; colaborar com o aperfeiçoamento dos cursos jurídicos, e opinar, previamente, nos pedidos apresentados aos órgãos competentes para criação, reconhecimento ou credenciamento desses cursos e autorizar, pela maioria absoluta das delegações, a oneração ou alienação de seus bens imóveis e participar de concursos públicos, nos casos previstos na Constituição e na lei, em todas as suas fases, quando tiverem abrangência nacional ou interestadual.

A diretoria do Conselho Federal é composta de um Presidente, de um Vice-Presidente, de um SecretárioGeral, de um Secretário-Geral Adjunto e de um Tesoureiro.O Presidente exerce a representação nacional e internacional da OAB, competindo-lhe convocar o Conselho Federal, presidi-lo, representá-lo ativa e passivamente, em juízo ou fora dele, promover-lhe a administração patrimonial e dar execução às suas decisões.

\section{Os conselhos secionais}

Órgãos dotados de personalidade jurídica própria têm jurisdição sobre os respectivos territórios dos Estados-membros, do Distrito Federal e dos Territórios.O Conselho Secional compõe-se de conselheiros em número proporcional ao de seus inscritos, segundo critérios estabelecidos no regulamento geral, ou seja, a Lei $\mathrm{n}^{\circ} 8.906$, de 04 de julho de 1.994

São membros honorários vitalícios os seus ex-presidentes, somente com direito a voz em suas sessões. O Presidente do Instituto dos Advogados local é membro honorário, somente com direito a voz nas sessões do Conselho. Quando presentes às sessões do Conselho Secional, o Presidente do Conselho Federal, os Conselheiros Federais integrantes da respectiva delegação, o Presidente da Caixa de Assistência dos Advogados e os Presidentes das Subseções, têm direito a voz.

O Conselho Secional exerce e observa, no respectivo território, as competências, vedações e funções atribuídas ao Conselho Federal, no que couber e no âmbito de sua competência material e territorial, e as normas gerais estabelecidas nesta lei, no regulamento geral, no Código de Ética e Disciplina, e nos Provimentos.

Compete privativamente ao Conselho Secional: editar seu regimento interno e resoluções; criar as Subseções e a Caixa de Assistência dos Advogados; julgar, em grau de recurso, as questões decididas por seu Presidente, por sua diretoria, pelo Tribunal de Ética e Disciplina, pelas diretorias das Subseções e da Caixa de Assistência dos Advogados;fiscalizar a aplicação da receita, apreciar o relatório anual e deliberar sobre o balanço e as contas de sua diretoria, das diretorias das Subseções e da Caixa de Assistência dos Advogados;fixar a tabela de honorários, válida para todo o território estadual; realizar o Exame de Ordem; decidir os pedidos de inscrição nos quadros de advogados e estagiários; manter cadastro de seus inscritos; fixar, alterar e receber contribuições obrigatórias, preços de serviços e multas; participar da elaboração dos concursos públicos, em todas as suas fases, nos casos previstos na Constituição e nas leis, no âmbito do seu território; determinar, com exclusividade, critérios para o traje dos advogados, no exercício profissional; aprovar e modificar seu orçamento anual;definir a composição e o funcionamento do Tribunal de Ética e Disciplina, e escolher seus membros; eleger as listas, constitucionalmente previstas, para preenchimento dos cargos nos tribunais judiciários, no âmbito de sua competência e na forma do Provimento do Conselho Federal, vedada a inclusão de membros do próprio Conselho e de qualquer órgão da OAB e intervir nas Subseções e na Caixa de Assistência dos Advogados.

A diretoria do Conselho Secional tem composição idêntica e atribuições equivalentes às do Conselho Federal, na forma do regimento interno daquele.

\section{As caixas de assistência dos advogados}

Órgãos dotados de personalidade jurídica própria são criados pelos Conselhos Secionais, quando estes contarem com mais de mil e quinhentos inscritos, com personalidade jurídica própria, destina-se a prestar assistência aos inscritos no Conselho Secional a que se vincule. A Caixa é criada e adquire personalidade jurídica com a aprovação e registro de seu estatuto pelo respectivo Conselho Secional da $\mathrm{OAB}$, na forma do regulamento geral. A Caixa pode, em benefício dos advogados, promover a seguridade complementar $\left(\S 2^{\circ}\right.$, art. 62 da Lei $\left.n^{\circ} 8.906 / 94\right)$.

\section{As Subseções}

As Subseções são partes autônomas do Conselho Secional e pode ser criada pelo Conselho Secional, que fixa sua área territorial e seus limites de competência e autonomia. A área territorial da Subseção pode abranger um ou mais municípios, ou parte de município, inclusive da capital do Estado, contando com um mínimo de quinze advogados, nela profissionalmente domiciliados. A Subseção é administrada por uma diretoria, com atribuições e composição equivalentes às da diretoria do Conselho Secional. Havendo mais de cem advogados, a Subseção pode ser integrada, também, por um conselho em número de membros fixado pelo Conselho Secional.Cabe ao Conselho Secional fixar, em seu orçamento, dotações específicas destinadas à manutenção das Subseções. O Conselho Secional, mediante o voto de dois terços de seus membros, pode intervir nas Subseções, onde constatar grave violação desta lei ou do regimento interno daquele. Compete à Subseção, no âmbito de seu território: dar cumprimento efetivo às finalidades da $\mathrm{OAB}$; velar pela dignidade, independência e valorização da advocacia; fazer valer as prerrogativas do advogado; representar a OAB perante os poderes constituídos e desempenhar as atribuições previstas no regulamento geral ou por delegação de competência do Conselho Secional (arts. 60 e 61 da Lei no $8.906 / 94$ ).

\section{A $5^{\mathrm{a}}$ subseção da ordem dos advogados do brasil em Araraquara}

A $5^{\text {a }}$ Subseção da Ordem dos Advogados do Brasil em Araraquara contribui incansavelmente pela mantença da democracia e cidadania na cidade de Araraquara.A Subseção de Araraquara foi criada em 21 de março de 1.932, ano simbólico como já dito em lutas pelo Estado Democrático de Direito. Realizou sua primeira eleição de Diretoria da Subseção no dia 02 de abril de 1.933. Esse ano de 2.017 em que a cidade de Araraquara completa 200 anos a $5^{\text {a }}$ Subseção completa 85 anos de existência.No ato de fundação e eleição de diretoria estavam presentes sete advogados e aclamaram como primeiro Presidente da Subseção o digníssimo advogado Augusto Freire da Silva Júnior com seis votos contra um voto do digníssimo advogado Christiano Infante Vieira.A Subseção de Araraquara tinha como sede provisória para reuniões o prédio da antiga Cadeia Pública, situada na época à Rua Padre Duarte esquina com a Rua José Bonifácio, onde hoje se encontra estabelecido o Pronto Socorro Municipal. Em outras ocasiões foram realizadas reuniões no próprio escritório do então Presidente da Subseção onde deliberações administrativas pertinentes às atividades da Subseção foram procedidas.

Esses são alguns detalhes de nossa honrosa e querida Subseção de Araraquara a quinta a ser criada no Estado, mostrando a sua importância (ORDEM DOS ADVOGADOS DO BRASIL - 5 $5^{\text {a }}$ SUBSEÇÃO DE ARARAQUARA,2017).

A Subseção de Araraquara é um exemplo de evolução da própria Ordem dos Advogados do Brasil, representa a força da Advocacia Paulista, que capitaneada pelo advogado José Wellington Pinto que foi o primeiro advogado do interior a compor uma diretoria da Secional Paulista na história da OAB de São Paulo, como Secretário Adjunto. O mesmo advogado antes havia presidio a poderosa $5^{\text {a }}$ Subseção de Araraquara e igualmente representou a Advocacia de Araraquara nas cadeiras o Conselho Estadual. 


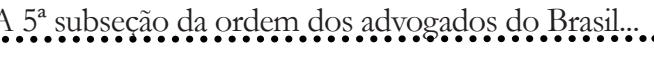

A $5^{\text {a }}$ Subseção sempre primou por ser mais que uma mera entidade de classe e sim cumprir com exatidão a sua função social que é defender a democracia e o estado democrático de direito. Tanto é verdade que sempre participou dos conselhos democráticos do poder executivo, judiciário e legislativo da cidade, participando ativamente através de advogados e advogadas voluntários em reuniões, projetos e iniciativas que visam contribuir com a cidadania. Conselhos estes que, muitas das vezes o membro indicado pela $5^{\text {a }}$ Subseção assumiu a condição de presidente.

Além, disso a $5^{\text {a }}$ Subseção mantêm dezenas de comissões temáticas que garantem ao cidadão e aos demais poder constituídos da cidade uma prestação de serviçode excelência. Podemos citas as seguintes comissões:

Comissão de Ética e Disciplina que proporciona sempre a fiscalização do exercício profissional, garantido a ética e retidão do advogado que milita na cidade.

Comissão da Verdade sobre a Escravidão Negra em Araraquara que composta por profissionais multidisciplinares fez um estudo histórico dos casos de escravidão em Araraquara, para envio a OAB São Paulo para apresentação posterior ao Conselho Federal.

Comissão de Combate ao Exercício Irregular de Profissão e de Defesa das Atividades Privativas da Advocacia garantindo que somente advogados e advogadas possam prestar serviços jurídicos ao cidadão, com fiscalização e qualidade.

Comissão da Assistência Judiciária e Coordenadoria de Assistência Judiciária emprestando advogados e advogadas que mediante o convênio com o Estado prestam serviços jurídicos aos cidadãos carentes de Araraquara e região com excelente qualidade. A OAB mantêm estrutura e pessoal destinado a esse fim, contribuindo gratuitamente com a garantia de que todo cidadão carente tenha uma assistência jurídica gratuita. Comissão de Infância e Juventude destinada a fazer cumprir o Estatuto da Criança e do Adolescente, zelando por esses direitos na cidade.

Comissão da Justiça do Trabalho e de Estudos do Direito do Trabalho, fiscalizando pela defesa intransigente do direito do trabalhador araraquarense.

Comissão de Acompanhamento Legislativo onde a Subseção atua diretamente no Poder Legislativo local assessorando ou questionando a legalidade ou constitucionalidade das leis municipais.

Comissão de Auditoria de Urnas Eletrônicas onde a Subseção auxilia na fiscalização das eleições municipais. Comissão de Combate a Discriminação zelando para que nenhum cidadão sofra qualquer tipo de discriminação ou preconceito.

Comissão de Direito Desportivo, Esporte e Lazer incentivando a prática de atividade física e de lazer

Comissão de Direito Eletrônico e Crimes de Alta Tecnologia onde advogados e advogadas especializados no assunto prestam serviços a comunidade principalmente em relacionamentos em redes sociais etc.

Comissão de Direito Empresarial e Governança Corporativa organizando cursos e palestras tendentes a fomentar o direito empresarial local.

Comissão de Direitos das Pessoas com Deficiência, assessorando órgãos e entidades sobre referidos direitos dos portadores de necessidades especiais.

Comissões do Ensino Jurídico e OAB Vai à Escola, garantindo que seja levado aos alunos conceitos como: cidadania, direito, estado democrático etc.

ComissãodeExamedeOrdemgarantidoqueoscidadãosdeAraraquarafaçam suaprovadeadmissãoaquimesmo na cidade sem ter que se deslocar para outras comarcas e garantido a qualidade do saber jurídico dos aprovados. Comissão de Grupo de Estudos que visa aprimorar o conhecimento jurídico dos operadores do direito local. Comissão de Sociedade de Advogados que visa atender os advogados e advogadas locais na criação de uma pessoa jurídica.

Comissão do Direito Religioso que visa eliminar qualquer discriminação contra religiões.

Comissão de Proteção e Defesa dos Animais que atua diretamente junto ao Poder Público, orientando, educando e buscando punição as violações.

Comissão de Direitos Humanos a mais utilizada pela população de Araraquara que vê com muita seriedade esse braço da defesa dos direitos humanos na cidade.

ComissãodoAdvogadoPrevidenciárioque esclareceeauxiliaasmudançasealteraçõesdodireitoprevidenciário. Comissão do Advogado Público que regula a atuação desse profissional perante a sociedade civil.

Comissão de Direito do Consumidor que educa, fiscaliza e busca o cumprimento das leais de defesa do consumidor. Comissão do Fórum Federal e Estadual tendente a zelar pelo bom funcionamento do Poder Judiciário
Comissão do Jornal da OAB e do Site da OAB que visa difundir os cursos, eventos e direitos não somente os advogados e advogadas, mas igualmente a toda a Sociedade Civil.

Comissão do Jovem Advogado que visa à inserção do advogado araraquarense recém-formado ao mercado de trabalho.

Comissão no Novo Código de Processo Civil que visa estudar conjuntamente as alterações legislativas do novo código.

Comissão do Processo Eletrônico que visa garantir o pleno acesso à justiça através da implantação do processo judicial eletrônico.

Comissão do Sindicato dos Advogados que visa à garantia dos direitos trabalhista da classe.

Comissão dos Advogados Correspondentes de Araraquara visando orientar os advogados e advogadas de Araraquara que prestaram serviços a outros escritórios da capital e região.

Comissão dos Convênios Regionais que visa à implantação de convênios entre a $\mathrm{OAB}$ e o comércio local para fomento comercial.

Comissão especial LGBT que visa à proteção contra a discriminação, ficando à disposição da sociedade de Araraquara para atuação.

Comissão do Meio Ambiente que atua diretamente junto à municipalidade para proteção e preservação do meio ambiente local.

Comissão da Mulher Advogada que a nível municipal atua em defesa das mulheres vítimas de violência.

Comissão da $\mathrm{OAB}$ Concilia que incentiva a disponibiliza um programa de mediação e conciliação gratuito à população.

Comissão de Direito de Família que se dedica ao estudo e aprimoramento de tão importante ramo do direito. E por fim a Comissão de Cultura e Eventos que organiza eventos, cursos e palestras abertas à população.

Frisa-se que todos esses serviços são prestados à população da morada do sol sem custo algum, suprindo muitas das vezes a ineficiência do Poder Público.

$\mathrm{Na}$ cidade de Araraquara contamos uma unidade da Defensoria Pública do Estado de São Paulo que mediante convênio com a Ordem dos Advogados do Brasil e a Instituição da Defensoria Pública celebrado no âmbito estadual ambas as instituições garantem a cidadania aos cidadãos carentes de Araraquara.

A Subseção possui mais de 1.700 advogados e advogadas inscritos, bem como centenas de estagiários e estagiárias, cujos números sem ascensão provam a importância de destaque da subseção no contexto regional que a cidade de Araraquara se encontra.

A $5^{\text {a }}$ Subseção mantêm ainda sedes e unidades totalmente estruturadas com material físico e humano, uma Oitava Turma do Tribunal de Ética e Disciplina que visa acelerar o processamento e julgamento das faltas éticas e disciplinares cometidas por advogados e advogadas em tempo hábil. Encontra-se instalada ainda na Subseção uma sede regional da Escola Superior da Advocacia que contribui para o aprimoramento intelectual de advogados, advogadas, estagiários e estagiárias da cidade de Araraquara. Veja-se que com a presença da $5^{\mathrm{a}}$ subseção da Ordem dos Advogados do Brasil todos esses serviços são prestados na cidade de Araraquara contribuindo para com o aperfeiçoamento local.

Na nossa cidade de Araraquara temos a Coordenação Regional de um polo de Defesa das Prerrogativas do Advogado, onde qualquer violação do direito de defesa do cidadão pode ser processada e resolvida aqui mesmo na cidade, sem que o cidadão araraquarense seja vítima de uma violação em seu direito e tenha que buscar reforço apenas na capital bandeirantes.

Em recente reestruturação da Casa da Advocacia e Cidadania da OAB de Araraquara, o cidadão pode se dirigir e sem custo algum solicitar qualquer defesa de um direito que está sendo violado, onde através de uma estruturação a $5^{\text {a }}$ Subseção poderá atender, encaminhar e reestabelecer o direito desse cidadão que até então estava sendo usurpado.

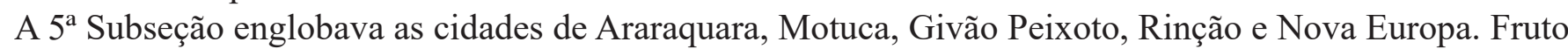
do trabalho e empreendedorismo em ...foi criada a Subseção de Américo brasiliense que Hoje engloba além da cidade de Amerilhense as cidades de Rincão, Motuca e Gavião Peixoto.

\section{CONSIDERAÇÕES FINAIS}

A $5^{\text {a }}$ Subseção da Ordem dos Advogados do Brasil sediada em Araraquara nesse ano em que completa 85 anos de existência é uma instituição que garante o exercício pelo da cidadania e do estado democrático de Revista Brasileira Multidisciplinar - ReBraM vol 20, (supl.) n.1 - Araraquara 200 anos 
direito na nossa querida cidade de Araraquara que nessa mesma data completa os seus 200 anos de existência.

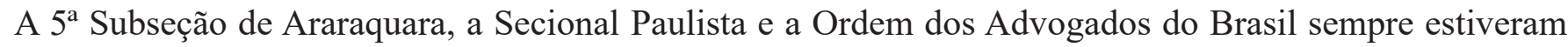
presentes nos principais episódios em que a varonil cidade de Araraquara precisou de seus braços fortes e com certeza existirão sempre ombreadas com a Morada do Sul por centenas de anos.

\section{REFERÊNCIAS}

BATOCHIO, José Roberto. A inviolabilidade do advogado. São Paulo: OAB-SP, 1992.

BRASIL. Lei 8906, de 04 de julho de 1994. Dispõe sobre o Estatuto da Advocacia e a Ordem dos Advogados do Brasil (OAB). Disponível em: http://www.planalto.gov.br/ccivil_03/leis/L8906.htm. Acesso em: 12 de fev. 2017.

BULOS, UadiLâmego. Constituição federal anotada. São Paulo: Saraiva, 2003.

CARNELUTTI, Francesco. Metodologia do direito. Campinas, Bookseleer, 2002.

LOBO, Paulo Luiz Neto. Comentários ao novo estatuto da advocacia e da OAB. Brasília: Brasília Jurídica, 1994.

MACHADO, Rubens Approbato. História da ordem dos advogados do Brasil, luta pela criação e resistências. Brasília: Conselho Federal da OAB, 2004.

ORDEM DOS ADVOGADOS DO BRASIL - 5 SUBSEÇÃO DE ARARAQUARA. Disponível em $\underline{\text { http:// }}$ www.oabararaquara.com.br/. Acesso em: 12 de fev. 2017.

ORDEM DOS ADVOGADOS DO BRASIL. Portal OAB Conselho Federal. Disponível em http://www. oab.org.br/historiaoab/antecedentes.htm. Acesso em 12 de fev. .

PREFEITURA MUNICIPAL DE ARARAQUARA. Disponível em http://www.araraquara.sp.gov.br/. Acesso em: 12 de fevereiro de 2017

RAMOS, Gisela Gondin. Estatuto da advocacia: comentários e jurisprudência selecionada. 4. ed. Florianópolis: $\mathrm{OAB} / \mathrm{SC}, 2003$.

ROLLO, A; FERNANDES, P. S. L. Na defesa das prerrogativas do advogado. São Paulo: OAB-SP, 2000.

ROUSSEAU, Jean-Jacques. Discurso sobre a origem e os fundamentos da desigualdade entre os homens. 2. ed. São Paulo: Martins Fontes, 2002.

SALDANHA, N. A OAB e sua trajetória. Recife: OAB-PE, 1982.

TELAROLLI, Rodolpho. Para uma história de Araraquara. Araraquara: Editora Unesp, 2003.

TORON, Alberto Zacharias; SZAFIR, Alexandra Lebelson. Prerrogativasprofissionais do advogado. 3.ed. São Paulo: Atlas, 2010.

Portal OAB Conselho Federal. Disponível emhttp://www.oab.org.br/historiaoab/antecedentes.htm. Acesso em

12 de fevereiro de 2017. 